\title{
Experiências de ressignificação de tradições carnavalescas em Podence e Ovar, Portugal
}

Experiences of re-signification of carnival traditions in Podence and Ovar, Portugal

Experiencias de resignificación de tradiciones carnavalescas en Podence y Ovar Portugal

http://dx.doi.org/10.18472/cvt.17n1.2017.1148

Marcos Luiz Filippim 〈marcoslupim@yahoo.com.br > Universidade Federal do Paraná (UFPR), Curitiba, PR, Brasil.

Miguel Bahl <migbahl@gmail.com >

Universidade Federal do Paraná (UFPR), Curitiba, PR, Brasil.

CRONOLOGIA DO PROCESSO EDITORIAL

Recebimento do artigo: 24-out-2015

Aceite: $20-d e z-2016$

FORMATO PARA CITAÇÃO DESTE ARTIGO

FILIPPIM, M. L.; BAHL, M. Experiências de ressignificação de tradições carnavalescas em Podence e Ovar, Portugal. Caderno Virtual de Turismo. Rio de Janeiro, v. 17, n. 1, p. 155-170, abr. 2017.

REALIZAÇÃO

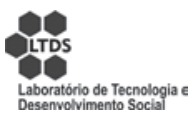

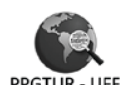

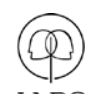

IABS
APOIO INSTITUCIONAL

COPPE

UFR]

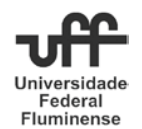

EDIÇÃO

EDITORA
PATROCÍNIO

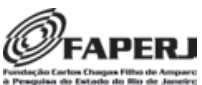




\section{RESUMO}

O objetivo deste artigo consistiu em avaliar experiências de ressignificação de tradições carnavalescas nas localidades de Ovar e Podence, em Portugal. Na pesquisa, realizada em 2013, se adotou abordagem qualitativa, com delineamento de estudo de caso e foram empregadas técnicas como entrevistas narrativas, registros em caderno de campo, observação participante periférica e análise de documentos. Os resultados indicaram que os seguintes aspectos foram relevantes no processo de ressignificação das tradições em exame: influência do turismo, espetacularização e transformação de rituais em performances, textualizações acadêmicas e jornalísticas, seleção de conteúdos culturais pelos organizadores, e a própria natureza dinâmica das tradições. No entanto, constatou-se que apesar das manifestações culturais estarem sendo ressignificadas considerou-se a ressalva de que as mudanças de características se colocavam como alternativa ao seu desaparecimento uma vez que davam mostras de fragilização antes de serem reabilitadas como atrações turísticas.

Palavras-chave: Ressignificação de Tradições. Carnaval. Turismo Cultural. Carnaval em Portugal. Caretos de Podence.

\section{ABSTRACT}

The aim of this article consisted of evaluating experiences of re-signification of carnival traditions in the localities of Ovar and Podence, in Portugal. In the research, held in 2013, it was adopted a qualitative approach, with case study design, and techniques were employed, like narrative interviews, recordings in fieldwork notebook, peripheral participant observation and document analysis. The results indicated that the following aspects were relevant in the re-signification of the traditions in question: influence of the tourism, spectacularization and transformation of rituals in performances, academic and journalistic writings, selection of cultural contents by the organizers, and the own dynamic nature of the traditions. However, it was found that although the cultural manifestations are being re-signified, it was considered the reservation that the changes of characteristics were presented as alternative to their disappearance, once they showed weakening before being rehabilitated as touristic attractions.

Keywords: Re-signification of traditions. Carnival. Cultural Tourism. Carnival in Portugal. Caretos of Podence.

\section{RESUMEN}

El objetivo de este artículo consistió en evaluar experiencias de resignificación de tradiciones carnavalescas en las localidades de Ovar y Podence, en Portugal. En la investigación, realizada en 2013, se adoptó abordaje cualitativo, con delineamiento de estudio de caso y fueron empleadas técnicas como entrevistas narrativas, registros en cuadernos de campo, observación participante periférica y análisis de documentos. Los resultados indicaron que los siguientes aspectos fueron relevantes en el proceso de resignificación de las tradiciones en examen: influencia del turismo, espectacularización y cambio de rituales en performances, textualizaciones académicas y periodistas, selección de contenidos culturales por los organizadores y la propia naturaleza dinámica de las tradiciones. Sin embargo, se constató que mismo que las manifestaciones culturales estén siendo resignificadas se consideró la condición de que los cambios de características se ponían como alternativa a su desaparecimiento, una vez que daban muestras de fragilidad antes de ser rehabilitadas como atracciones turísticas.

Palavras clave: Resignificación de tradiciones. Carnaval. Turismo Cultural. Carnaval en Portugal. Careto de Podence. 


\section{Introdução}

A pesquisa que deu origem a este artigo compõe um estudo mais amplo, acerca das tradições de Carnaval brasileiras e portuguesas. No caso específico deste trabalho são comunicados os resultados obtidos na investigação realizada em Portugal entre os meses de setembro e dezembro de 2013.

A proposta inicial do estudo consistia em discutir a conformação dos festejos de Carnaval no Norte de Portugal. No entanto, o pressuposto de que se tratava de um evento com características homogêneas nas diferentes localidades em que a manifestação apresentava alguma importância no âmbito da atração de visitação turística foi logo desfeita pelas primeiras leituras e coleta de informações de campo.

Ainda que a área espacial abrangida pelo estudo seja relativamente reduzida, a conformação dos festejos apresentou características completamente distintas entre si. Assim, julgou-se adequado estudar pelo menos duas vertentes do Carnaval no Norte português e foram eleitos os eventos de Ovar, no Litoral; e Podence, que se situa na Região de Trás-os-Montes. A escolha deu-se em função de que tais manifestações representavam modelos marcadamente diferentes entre si, mas que passaram, ambos, por um processo de ressignificação de suas tradições carnavalescas. Na pesquisa aqui proposta se buscou evidências de alterações nessas festividades, decorrentes da diversidade de interesses e expectativas dos turistas que visitavam a região para participar do evento.

Nessa perspectiva, na investigação se propôs a responder as seguintes indagações: $\mathrm{o}$ formato da festa e a própria paisagem cultural eram influenciados pela visitação? Os organizadores de tais eventos realizavam, intencionalmente ou não, um esforço para manter ou reproduzir aspectos que julgavam ser autênticos ou tradicionais? Diante de tais considerações, o problema de pesquisa ficou assim erigido: como os organizadores percebiam e representavam o Carnaval e as expectativas dos frequentadores desse evento nas localidades de Ovar e Podence, em Portugal, e como isso alterava, ou não, o formato da manifestação?

O objetivo da investigação aqui relatada consistiu em avaliar experiências de ressignificação de tradições carnavalescas nas localidades de Ovar e Podence, em Portugal. No que concerne à estratégia de pesquisa, adotou-se uma perspectiva qualitativa com delineamento de estudo de caso. Para Yin (2001), esse design de pesquisa consiste em uma investigação de natureza empírica em que se estuda um fenômeno dentro de seu contexto real em especial quando os limites entre o fenômeno e esse contexto não estão claramente definidos. Também foram empregadas técnicas como entrevistas narrativas, visitação aos locais selecionados, registros em caderno de campo, observação participante periférica e análise de documentos.

Os respondentes da entrevista foram os organizadores do Carnaval nas localidades selecionadas, aqui entendidos como gestores dos eventos, além de serem consideradas figuras ou autoridades relevantes para a manifestação cultural em exame. O critério de escolha foi a recorrência em que foram citados por populares como detentores de um profundo conhecimento acerca do objeto de estudo. Outro aspecto considerado foi a condição de comando ou influência na organização do evento. Raposo (2010) chama esses tipos de informantes de indivíduos "medulares" para a pesquisa.

Foram feitas entrevistas semiestruturadas nos meses de outubro e novembro de 2013, com o presidente do Grupo de Caretos de Podence, principal responsável pelo Carnaval local, que neste artigo será identificado como Informante 1, ou "INF. 1", e com o vereador da Cultura e membro da extinta Fundação do Carnaval de Ovar, gestor público responsável pela organização do Carnaval na cidade, aqui 
identificado como Informante 2, ou "INF. 2". Além das entrevistas, que foram gravadas e transcritas, ocorreram inúmeras conversas informais e recolha de material de campo. Os depoimentos gravados tiveram duração média de cinquenta minutos cada e foram realizados em locais previamente escolhidos pelos respondentes.

$\mathrm{Na}$ estrutura deste trabalho se contempla, além desta nota introdutória, uma discussão sucinta acerca da origem e evolução dos festejos de Carnaval, seguida da caracterização da festa no Norte de Portugal, que corresponde à análise dos resultados obtidos. Seguem-se ainda as conclusões do estudo e, ao final, as referências utilizadas.

\section{Os festejos de Carnaval: origem, evolução e etimologia}

A origem dos festejos de Carnaval é controversa. Enquanto verifica-se que uma parcela dos historiadores situa evidências das manifestações ainda na Antiguidade, outra vertente sustenta que é mais adequado usar o termo para denominar a festa a partir da Idade Média.

De acordo com Muniz Júnior (2003), o Carnaval tem sua gênese em cerimônias pagãs da Antiguidade, sendo que há registros de sua ocorrência em diferentes culturas, como no Egito, Grécia, Roma, China e Índia. Os rituais envolviam homenagens a deuses e semideuses dessas civilizações, tais como, Baco, Pan, Saturno e o irreverente Momo que, segundo Franchini e Seganfredo (2007, p. 472), pode ser qualificado como a "[...] personificação do Sarcasmo. Entre os gregos é uma divindade feminina, filha da Noite e irmã das Hespérides. Entre os romanos, é o deus da alegria e dos festejos”.

Martins (2009) lembra que no Egito Antigo era promovida uma festa durante o plantio em homenagem à Deusa Ísis, protetora da natureza, para garantir uma boa colheita. De forma análoga, na Babilônia, a chegada da primavera era comemorada com uma festa em homenagem a Marduk, o Deus Supremo. Nesse período, a escravidão era abolida temporariamente. Além disso, durante os 11 dias dos festejos, era empossado um rei (em caráter excepcional), que ao final seria açoitado e sacrificado para que a divindade permitisse a fertilidade das sementes.

Na Grécia, ainda de acordo com Martins (2009), o culto a Dionísio seria oficializado sob o governo de Psístrato (605-527 a.C.). Nessa celebração, organizada por camponeses, se realizavam procissões conhecidas como Dionisíadas nas quais uma embarcação com rodas (carrum navalis) transportava a imagem do deus. O mesmo autor assinala que a insólita composição de carro e navio simbolizava a ideia de que Dionísio havia chegado a Atenas pelo mar, mas seria acompanhado pelos sátiros (semideuses que habitavam a floresta e possuíam pés de bode). No cortejo do carro, em que vinham homens e mulheres nus dançando em festa, seguia uma multidão de pessoas mascaradas e um touro que posteriormente seria sacrificado em um templo onde se consumava o casamento de Dionísio com a polis (hierogamia) o que iria proporcionar a fecundação coletiva (MARTINS, 2009).

O mesmo autor prossegue explicando que entre os romanos eram realizadas as Saturnálias, em honra ao Deus da Agricultura, Saturno, que teria sido expulso do Olimpo por defender a igualdade entre os homens e era saudado no início da primavera para festejar a liberdade e, nessas ocasiões, os escravos assumiam o lugar de seus senhores. Ainda para Martins (2009), na Roma Antiga eram celebradas as Lupercais, em homenagem ao Deus Pã. Como se pode constatar, é possível identificar alguns pontos de convergência entre as concepções das festas na Antiguidade: há uma recorrência da ideia de fertilidade 
garantida por uma divindade como contrapartida à homenagem prestada no ritual. Além disso, outro elemento comum consiste na flexibilização provisória de normas sociais e mesmo da hierarquia de poder, como é o caso da abolição da escravidão e escolha de um rei para governar extraordinariamente durante os festejos.

No entanto, convém lembrar que essa aparente anomia tem um caráter provisório, como se fosse uma condição de exceção em relação ao cotidiano. Além disso, tanto em suas origens na Antiguidade quanto nas manifestações contemporâneas, o Carnaval pode funcionar como um elemento de reforço da ordem social (MARTINS, 2009; RAPOSO, 2010).

Assim, se estabelece um paradoxo entre a percepção corriqueira da festa como vetor de contestação do status quo, já que ela parece funcionar como elemento de contenção das pulsões sociais e, em última análise, uma forma segura e controlada de lidar com essas tensões. Assim como a origem da festa em si, também a raiz etimológica da palavra "Carnaval" é controvertida. Martins (2009) apresenta algumas hipóteses de explicação para o surgimento do termo. Segundo esse autor, a palavra Carnaval pode ser a contração da expressão carrum navalis, usada para qualificar os carros navais utilizados nas festas dionisíacas gregas nos séculos VII e VI a.C. Embora essa explicação também seja compartilhada por vários historiadores, ainda são aventadas outras possibilidades:

[...] outros autores colocam sua origem em Gregório I em 590 d.C., o qual transportou o início da Quaresma para a quarta-feira antes do sexto domingo que precede a Páscoa. Ao sétimo domingo, denominado quinquagésima, deu o nome de 'domenica ad carne lavandas', expressão que seria sucessivamente abreviada para 'carne levale, 'carne levamen', 'carnevale' e 'carnaval' de acordo com os vários dialetos italianos [...]. A terça-feira Mardi-Gras, seria a noite de Carnaval, ou seja, a noite da permissão de se comer carne antes dos 40 dias de jejum (Quaresma) (MARTINS, 2009, p. 130)

Em seu exame etimológico para o surgimento do termo, Martins (2009) também levanta a possibilidade de que a palavra Carnaval venha da junção de "Kane" ou "Karth" que significa "lugar santo", e "Val" ou "Wal", cujo significado é "morto". O mesmo autor explica que, quando composta, a expressão pode ser entendida como "procissão dos deuses mortos", ou a procissão realizada pelas almas do Purgatório em busca de purificação, no dia de Ano Novo.

A relação com o calendário religioso também é levantada na proposição de Rosário (2008, p. 26) para esclarecer o surgimento do termo na era cristã: "[...] a palavra Carnisvalerium: Carnis, de carne, valerium, de adeus, ou seja, apontaria o 'adeus à carne' em função da quadra seguinte, a Quaresma, onde a carne não é permitida na alimentação dos cristãos".

Assim exposto, se verifica que a simbiose entre religioso e profano se revela inclusive nas raízes etimológicas da palavra Carnaval e de sua equivalente "Entrudo", termo mais utilizado no âmbito das festas realizadas no meio rural português para denominar a entrada da Quaresma (ROSÁRIO, 2008).

Essa polêmica tem gerado grandes debates entre os estudiosos do tema, como assinala Raposo (2010), para quem os esforços para descobrir as origens do Carnaval passam pela etimologia, que remete ao latim carnelevare ou carnevale (adeus à carne) e pela "[...] ciclicidade e calendarização - articulação dos tempos e ritmos sazonais, agrícolas, religiosos e sociais - ou pela sua eficácia ritual - decorrente de componentes ritualistas de sociedades antigas da Mesopotâmia, Grécia e Roma" (RAPOSO, 2010, p. 79).

O mesmo autor também observa que a articulação com a civilização europeia produziu práticas de origens variadas ao longo do tempo e que, embora mantenham relativa uniformidade de calendário, apresentam formas de manifestação muito distintas. 


\section{Podence, seus caretos e o Carnaval}

Antes de se discorrer sobre a caracterização da tradição carnavalesca de Podence, pareceu pertinente descrever sinteticamente a localidade e seu entorno. Segundo informações colhidas na página na Internet da Câmara Municipal de Macedo de Cavaleiros (2013), a Freguesia de Podence pertence, desde 1878, ao Concelho de Macedo de Cavaleiros, Distrito de Bragança, na Região de Trás-os-Montes, Nordeste de Portugal. No mesmo sítio eletrônico consta que anteriormente, em 1832, a aldeia chamava-se Freguesia de Nossa Senhora da Purificação e pertencia ao Concelho de Bragança. Em 1852 passou a pertencer ao Concelho de Izeda e Comarca de Chacim, até 1878, quando passou à jurisdição de Macedo de Cavaleiros que assim permanecia até o momento em que este estudo foi realizado. Na mesma fonte constava ainda que a freguesia possuía uma área superficial de $1.433 \mathrm{ha}$, onde estavam vivendo 357 residentes e votavam 380 eleitores (CÂMARA MUNICIPAL DE MACEDO DE CAVALEIROS, 2013). O fato de haver mais eleitores que residentes pareceu revelador, já que presumivelmente a população menor de 18 anos não estava inscrita no cadastro eleitoral, o que indicaria que uma parcela significativa dos votantes não morava na aldeia, informação confirmada por um dos informantes (INF. 1, 2013). Isso sugeriu supor que mesmo os migrantes ainda estavam mantendo uma relação de pertença com sua terra natal.

Conforme Raposo (2010), a localidade destacou-se no passado pela produção de gêneros agrícolas como castanha, morango, centeio, trigo, batata e uva, mas estava marcada pela imigração e êxodo rural, e pode ter perdido entre 7\% e 12\% de sua população no período intercensitário entre 1991 e 2001.

Ao lado das atividades agrícolas e agropastoris, o turismo pareceu despontar como atividade econômica de alguma relevância, já que, conforme constante na página eletrônica da Câmara Municipal, havia duas unidades de Turismo Rural na aldeia, a Quinta da Moagem João do Padre e a Quinta do Azibo. Além disso, a mesma fonte indicava que se situava ali a Praia da Ribeira e o espaço que abrigaria o Campo de Golfe do Município, no Azibo. Ainda no âmbito do turismo, os Caretos de Podence constituíam um atrativo importante: "A sua singular tradição etnográfica, ligada à figura do Careto, é o ex-libris da freguesia, que poderá ser apreciado por alturas dos festejos carnavalescos na povoação e na Casa do Careto" (CÂMARA MUNICIPAL DE MACEDO DE CAVALEIROS, 2013).

O Carnaval de Podence é frequentemente qualificado como uma das manifestações do gênero mais autênticas e tradicionais em Portugal (ROSÁRIO, 2008; RAPOSO, 2010), ainda que os conceitos de "autenticidade" e "tradição" possam ter conotações polissêmicas.

O evento caracteriza-se fundamentalmente pela saída dos Caretos às ruas da aldeia, à época do Carnaval (RAPOSO, 2010). O mesmo autor explica que o termo "careto" é usado para designar o mascarado que, em Podence, sai às ruas com uma fantasia característica, posteriormente adaptada em casaco e calça (no passado tratava-se de uma manta) cobertos de franjas de lã colorida e acrescida de um capuz também feito da mesma lã e uma máscara de lata, que eventualmente também pode ser de couro ou madeira. A fantasia completa-se com chocalhos e adereços que são a ela pendurados.

Os chocalhos que o careto leva consigo atendem a um objetivo, conforme esclareceu um dos entrevistados da presente investigação:

Os caretos, o objetivo deles, são as mulheres solteiras acima de tudo, é chocalhar as mulheres, o ritual da fertilidade é bater com o chocalho nas nádegas das raparigas, é isso que move o careto, na sua gênese e ritual. É por isso que o careto é só homem, que está interdito ao sexo feminino [...] (INF. 1, 2013). 
Assim, a composição da fantasia apresenta uma correlação com o ritual executado pelo careto, daí a necessidade dos chocalhos. No mesmo sentido, o colorido da roupa e a própria performance dos mascarados pretendem funcionar como um mecanismo de sedução, conforme sugeriu o entrevistado (INF. 1, 2013): "O careto, com a sua forma de estar, a sua liberdade espontânea, todo seu misticismo que envolve essa figura e a sua cor, sua alegria, faz com que as pessoas, neste caso as mulheres, se sintam atraídas por estes trajes, por esta figura!"

Nesse sentido, os caretos descrevem a si próprios como figuras enigmáticas, sedutoras, diabólicas e misteriosas, contendo em sua página oficial na Internet, versões em diferentes línguas, o que se considerou como uma evidência que se tratava de uma estratégia de divulgação dirigida aos visitantes estrangeiros. Além disso, também destacaram a coexistência de elementos mágicos, profanos e religiosos e a tipicidade da indumentária, aspectos que fariam da visita ao evento de Podence uma experiência única e fascinante (ASSOCIAÇÃO DOS CARETOS DE PODENCE, 2013).

A sedução despertada pelos Caretos pode paradoxalmente encobrir também outros sentimentos, como o medo e o terror, já que as figuras têm uma natureza misteriosa e não estão sujeitas a nenhuma espécie de regramento moral, como assinala Rosário (2008, p. 38): "aos olhos do povo, o mascarado representa o diabo [...]. Dado existirem espaços onde os mascarados não podem fazer o seu exercício, como o adro da igreja e a própria igreja, estes locais servem de refúgio às moças e aos garotos, que têm medo de ser perseguidos".

A mesma autora sugere que a origem dos caretos está vinculada aos ciclos da natureza, como nas festas de Carnaval da Antiguidade:

\begin{abstract}
Estamos perante uma forma insólita de ritual carnavalesco, onde o binómio ‘Careto/rústico transmontano’ é garantia para uma fascinante experiência, ímpar na sedução e mistério. Mas, o que são afinal os Caretos? Os Caretos são personagens que representam figuras diabólicas e misteriosas, que todos os anos, desde tempos que se perdem na história, saem à rua no dia de Entrudo, aparecendo em magotes barulhentos, espalhando o terror, excitação e riso. A aparição dos Caretos de Podence, no Carnaval, simboliza a despedida do Inverno e louva a chegada da Primavera. O Carnaval é, assim, um rito entre o pagão e o religioso. Por um lado, temos os excessos do vinho, comida, etc., como nas antigas saturnais romanas e, por outro lado, o início da Quaresma, um período de contenção no calendário religioso (ROSÁRIO, 2008, p. 60).
\end{abstract}

O esvaziamento demográfico da região, decorrente da migração e emigração, assim como as influências externas e a dinâmica de urbanização quase levaram à extinção da tradição do Entrudo Chocalheiro, conforme assinalam Raposo (2010) e Rosário (2008), entre outras fontes.

$\mathrm{O}$ rápido processo de desaparecimento do ritual foi interrompido por acontecimentos que geraram certa visibilidade externa à aldeia de Podence e provocaram uma ressignificação do Carnaval. Nesse sentido, parece relevante mencionar a produção do filme "Máscaras", de Noémia Delgado, em 1976 (MÁSCARAS, 2013); a publicação de vários textos de antropólogos e outros intelectuais; a construção da Casa do Careto e as sucessivas apresentações do Grupo de Caretos em eventos e festivais, a partir de 1985 (RAPOSO, 2010). Perguntado sobre as causas da fragilização do ritual a partir da segunda metade do século XX, o presidente do Grupo de Caretos de Podence explicou:

Deve-se a dois fatos principais que foi a imigração [...] e depois a Guerra Colonial levou os jovens para pontos da África na defesa das colônias, e esta situação fez com que a tradição praticamente ficasse nas cinzas e só a partir de 1975, com a rodagem do filme de Noémia Delgado, 'As Máscaras', é que a tradição começa a ter uma nova dinâmica, e a partir de 1985, os caretos dão o primeiro salto fora do seu território natural, que foi a primeira deslocação a Coimbra e a partir daí os convites chegam de todo lado, a nível nacional e internacional com várias passagens por... Carnaval de Nice, Carnaval de Arezzo, em Itália, deslocações a Disneylandia, Paris, vários eventos em Espanha [...]. 
Não é fácil conciliar isso porque o pessoal aqui é um pessoal que faz disto um gosto e um orgulho de ser caretos e muitas vezes não temos disponibilidade para as solicitações (INF. 1, 2013).

A visibilidade proporcionada pelo filme, pelas excursões dos caretos e pelas próprias publicações acadêmicas gerou um interesse turístico pelo ritual transmontano, assim como despertou a atenção da imprensa, que passou a cobrir o evento e outras atividades dos caretos. Esse novo contexto provoca o ressurgimento do Entrudo que, embora tenha chegado à beira do desaparecimento, ganha um novo fôlego e novos contornos (INF. 1, 2013; RAPOSO, 2010).

A ideia de certo exotismo e de um retorno a rituais com uma aura de mistério passa então a atrair turistas interessados em sua tipicidade e na possibilidade de assistir a uma manifestação pretensamente genuína e imune à dinâmica de uniformização cultural (RAPOSO, 2010). No entanto, o autor também pondera que na exata medida em que o evento se turistifica, ele passa a apresentar novas feições e funcionalidades, perdendo sua característica ritual para assumir uma natureza performática.

\begin{abstract}
No contexto das recentes transformações no mundo rural nas últimas décadas, os campos semânticos destas performances são amplamente alargados, agora resgatadas do seu anunciado declíneo. Elas estão claramente ligadas a realidades contemporâneas como o turismo e a mercadorização cultural. A visibilidade destas comunidades emerge lado a lado com uma crescente demanda de exotismo e autenticidade. Tal como as reivindicações folcloristas de 'autenticidade' da cultura popular, estes recentes processos de turistificação revelam a procura de um 'passado nostálgico e genuíno’ no contexto do consumo turístico global da pós-ruralidade (RAPOSO, 2011, p. 131).
\end{abstract}

A inevitável perda de espontaneidade do evento foi percebida inclusive pelos seus promotores, como é possível observar pelos depoimentos colhidos. No entanto, pondera-se que essa seja a alternativa para a continuidade da manifestação.

[...] acho que... se não houvesse essa manifestação, hoje a tradição... penso que não existia, teria desaparecido completamente. Há antropólogos que... que muitas vezes até nos criticam por este modelo, que nós implementamos... [...] analisando a tradição no contexto de há vinte ou trinta anos era diferente, isso é uma evolução natural, [...] mas também as coisas têm que evoluir, [...] a tradição também teve que evoluir, mas dentro daqueles rituais autênticos e genuínos, para que ela possa, neste caso, passar de geração em geração chegando até ao século XXI e o objetivo é que ela também tenha continuidade, e acho que este modelo é o modelo certo para que esta tradição tenha a continuidade devida. [...]. Os tempos não são bons, mas nós temos uma grande força que é o símbolo do careto... o careto faz com que as pessoas venham até nós e que quem esteja cá também goste de receber e também proporcionar aqui uma grande alegria e uma grande emoção nos três dias do evento (INF. 1, 2013).

Como é possível inferir a partir do fragmento transcrito, o organizador do evento percebeu que a visibilidade conferida pela visitação e audiência do evento provocaram alterações na sua configuração. Observa, no entanto, que a dinâmica era previsível ou em suas palavras, "natural" (afinal tudo muda, especialmente no que tange ao universo em transição do entrevistado). A crítica dos antropólogos puristas, mencionada no depoimento, pareceu ser assimilada de maneira compreensiva, em que pese o fato de que o discurso do presidente do Grupo dos Caretos revelar que fazia uma relação de custo-benefício e ponderava que o resultado dessa equação implicava em optar entre o que reputava como evolução ou o completo desaparecimento da manifestação.

Assim, o entrevistado manifestou acreditar que o turismo determinava uma ressignificação interna e externa do evento, que perdeu algumas de suas características rituais e passava a apresentar uma natureza performática. 


\section{O Carnaval "tropical” em Ovar}

A apresentação das características do Carnaval de Ovar e a construção de uma tradição carnavalesca na cidade serão precedidas de uma caracterização sucinta do município.

A cidade de Ovar pertence ao Distrito de Aveiro e localiza-se na área Norte da região central de Portugal, conforme informações colhidas no Instituto Nacional de Estatística (2013), onde também constava que o município possuía uma população de 55.398 habitantes (INE, 2013).

No sítio eletrônico da Internet da Câmara Municipal de Ovar (2013) constava que a ocupação da área onde se situa a cidade remonta à Pré-História, já que as condições da região eram favoráveis ao estabelecimento de comunidades humanas primitivas. Nesse sentido, registra-se que "[...] uma linha de costa muito diferente da atual, uma zona lagunar propícia à caça e à pesca, solos leves e fáceis de trabalhar devem ter constituído, ao longo dos séculos, fatores de atração e de fixação de habitantes" (CÂMARA MUNICIPAL DE OVAR, 2013). Em que pese tal possibilidade, na mesma fonte se indicava que a efetiva ocupação humana da área ocorreu a partir do século XI, sendo provável que Ovar originou-se da fusão de aldeias próximas. O grande impulso demográfico aconteceria a partir do século XVIII, com a introdução de novas técnicas de pesca e conservação do pescado, ainda segundo informações do mesmo órgão público. Esse quadro, no entanto, sofreria alterações a partir do século XX:

O secular quadro rural e piscatório foi profundamente subvertido, no século XX, com a industrialização que, acelerara sobretudo a partir das décadas de 50 e 60, transformou Ovar num concelho totalmente diferente, onde mais de metade da população activa se emprega no sector secundário. Atualmente, Ovar é um concelho industrial com um leque muito variado de atividades (CÂMARA MUNICIPAL DE OVAR, 2013).

Além da inequívoca importância da atividade industrial, o turismo também pareceu despontar como alternativa de desenvolvimento da região. Nesse sentido, o Carnaval de Ovar vinha sendo considerado como uma das mais relevantes manifestações desse gênero em Portugal (COLARES PINTO, 1993; INF. 2, 2013) e o município também reunindo "[...] vastas áreas propícias ao mais diversificado tipo de atividades turísticas: quilômetros de praias enquadradas por pinhal e a beleza ímpar da Ria de Aveiro" (CÂMARA MUNICIPAL DE OVAR, 2013).

Ainda que o Carnaval de Ovar tenha origens mais remotas, a literatura local costuma apontar o ano de 1952 como a gênese do "Carnaval Organizado", feito recorrentemente atribuído a José Maria Fernandes Graça, Aníbal Emanuel da Costa Rebelo e José Alves Torres Pereira (COLARES PINTO, 1993; FERNANDES; ROCHA; RODRIGUES, 1993; VAZ PINTO, 2011).

A ruptura paradigmática representada pela organização do Carnaval gerou registros ambíguos, por vezes elogiosos e por outras levantando o problema classificado no fragmento abaixo como perda de espontaneidade da manifestação:

\footnotetext{
Em 1952 dá-se, certamente com as melhores intenções, a 'domesticação' do Carnaval. Sonhou-se [...] uma festa que cumprisse dois objetivos: a 'institucionalização' da alegria carnavalesca e a exploração do Carnaval como cartaz turístico poderoso. O futuro demonstraria que os dois fins são inconciliáveis e que qualquer um deles, só por si quanto mais os dois ao mesmo - era suficiente para matar o que de espontâneo, genuíno e puro havia na louca alegria dos vareiros. Mesmo o Carnaval Sujo, se não tivesse morrido às suas próprias mãos, vítima dos seus inevitáveis exageros, teria sossobrado (sic) às leis e regulamentos que foram aparecendo, não por vontade de quem brinca, mas pela de quem manda que se brinque e como se brinca (COLARES PINTO, 1993, p. 14).
} 
Em que pese a constatação da inevitável perda da aludida espontaneidade decorrente do que o autor chamou de "domesticação" do Carnaval e sua progressiva mercantilização, aspectos que também foram compartilhados por populares ouvidos informalmente no trabalho de campo desta pesquisa, o próprio autor irá afirmar em tom apoteótico, no desfecho do mesmo texto, que "[...] o Carnaval de Ovar, mau grado as corruptelas e importações, é, sem dúvida nenhuma, o maior e o mais português de todos os carnavais portugueses" (COLARES PINTO, 1993, p. 17 - Grifo do autor).

Um exame superficial do Carnaval de Ovar faz crer ao observador que o modelo da festa em tudo se assemelha ao evento congênere do Rio de Janeiro, no Brasil, guardadas, evidentemente, as proporções. Os desfiles das escolas de samba com suas alegorias; coreografias; fantasias; sambas-enredo animados por baterias que, por sua vez, seguem uma beldade escolhida como "Rainha", são alguns dos traços comuns aos modelos carioca e vareiro de Carnaval. Mesmo no plano abstrato, durante a pesquisa de campo constatouse um clima de rivalidade entre os componentes das diferentes agremiações que disputam o título de campeãs do Carnaval, tanto de um lado do Atlântico, como no outro.

Como o Brasil é um país de colonização portuguesa, seria plausível supor que na conformação das Festas de Momo no Rio de Janeiro os seus organizadores tivessem se inspirado no evento de Ovar, não fosse o fato de que tal modelo foi delineado antes na cidade brasileira que na portuguesa, conforme Colares Pinto (1993). Assim, observa-se aqui um fenômeno em que a criatura influencia o criador, por assim dizer, já que o Carnaval foi introduzido no Brasil por meio dos portugueses, mas retorna às terras lusitanas, pelo menos no caso de Ovar, com a formatação que lhe foi dada na ex-colônia (COLARES PINTO, 1993).

A observação de fotografias dos eventos permite concluir que inclusive os figurinos mínimos das passistas (biquínis ou top less com pinturas e adereços), que parecem naturais no Carnaval "tropical" tupiniquim, assumem contornos aparentemente pouco confortáveis quando adotados em Ovar, pois seu evento ocorre no inverno europeu.

Em que pesem as semelhanças aqui assinaladas, uma observação mais detalhada também evidencia algumas especificidades do Carnaval vareiro em relação ao carioca. Os grupos carnavalescos que desfilam em Ovar, embora lembrem os blocos brasileiros, usam fantasias muito elaboradas e, em alguns casos, até alegorias (no Brasil os carros alegóricos são quase exclusivamente apresentados por Escolas de Samba e não pelos blocos). Além disso, esses pequenos grupos, que raramente excedem aos vinte componentes, escolhem um tema e executam uma performance teatralizada na apresentação (INF. 2, 2013). Nesses casos, as músicas utilizadas não têm uma relação necessária com os clássicos gêneros do Carnaval (como o samba e as marchinhas), sendo frequente o uso da "pop music", inclusive em línguas diversas do português, como é possível observar em filmes produzidos pela extinta Fundação de Carnaval de Ovar (2012).

Apesar das transformações operadas na formatação dos grupos carnavalescos, estes parecem usufruir de um estatuto de originalidade ou singularidade local, mesmo nos primeiros estudos sobre o tema realizados na cidade:

\footnotetext{
Os grupos são, ainda, a ligação ao espírito inicial. Mas, vindo de fora ou germinando no seu interior, o ritmo e a cor de todos são cada vez mais 'canarinhos'. Dizem os 'espertos' na matéria que se trata de recuperar o que, há cinco séculos, levamos para o lado de lá do Atlântico e que os nossos irmãos brasileiros desenvolveram, enriqueceram e 'viraram' neste mexer envolvente, absorvente e trepidante. De tal maneira trepidante que nem os nossos característicos gigantones e cabeçudos aguentaram... e foram embora de vez, ao fim talvez de trinta anos (COLARES PINTO, 1993, p. 17).
} 
Em que pese o fato de o autor escrever o trecho transcrito para compor o prefácio de um livro acerca da história do Carnaval organizado em Ovar, em uma edição pretensamente apologética (a obra "O Carnaval de Ovar: 1952-1993” é uma publicação comemorativa, com o objetivo de promover o evento da cidade), não se pode menosprezar a ironia que subjaz ao discurso de Colares Pinto (1993). Esse caráter fica evidente quando alude ao desaparecimento de características entendidas como tradicionais da configuração anterior da manifestação, como os gigantones (grandes bonecos de personalidades influentes), que teriam sido solapados pelo novo formato do evento, marcadamente influenciado pelo modelo brasileiro.

Perguntado sobre tais mudanças e a aparente proximidade com o Carnaval brasileiro, um dos responsáveis pela organização da festa na cidade argumentou:

\begin{abstract}
Sim [confirmando que houve mudanças], em termos de organização. O conceito é o mesmo, [...] e depois [...], talvez há vinte e poucos anos que apareceram as escolas de samba. Algo que de alguma forma torna-se polêmico porque, com respeito ao Carnaval do Brasil, há sempre uma crítica da aproximação ao carnaval brasileiro, que não tem a ver conosco em algum sentido... Até acho que nós também temos muito a dizer sobre o que se passa no... nomeadamente no Rio... sobre o carnaval, não é, nossos antepassados, é outra história... mas aqui foi algo que apareceu novo há cerca de vinte e poucos anos, eu não consigo precisar. Naturalmente que a perspectiva veio valorizar também o Carnaval de Ovar, e portanto temos cerca de quatro escolas de samba, que existem neste momento. Mas diria que aquilo que é mesmo a nossa referência é o carnaval que nós chamamos de grupos carnavalescos ou grupos de passarela que é um carnaval que tem interação com as pessoas, onde há um tipo de vestimenta cômica, sempre mais neste sentido, de interagir [...]. Portanto, nesse nível há evolução sim nas técnicas, nos métodos de trabalho e etc. O conceito é mais ou menos o mesmo... foi-se perdendo algumas coisas boas, antigas, e foi-se ganhando outras.... conhecimento. (INF. 2, 2013).
\end{abstract}

Outra particularidade de Ovar consiste nas manifestações individuais de pessoas que se apresentam com placas onde são escritas anedotas e críticas à situação econômica e a figuras políticas locais, do país ou mesmo internacionais (INF. 2, 2013). Nesse sentido, o próprio Rei Momo e a Rainha do Carnaval, escolhidos entre os moradores da cidade, também fazem um pronunciamento jocoso e, por vezes, "decretam" a prisão ou condenação de figuras públicas envolvidas em ilícitos administrativos (FUNDAÇÃO DO CARNAVAL DE OVAR, 2012). Esse tipo de manifestação parece estar presente desde a gênese do Carnaval, como mencionou um dos entrevistados desta investigação:

[...] nós tínhamos um hábito que ainda estamos conseguindo que é [sic] as piadas ... são interlocutores que levavam uma placa, iam disfarçados de alguma coisa... que neste momento criticavam de alguma forma, mas havia a nossa polícia do Estado, da ditadura que era a chamada PIDE [Polícia Internacional e de Defesa do Estado, órgão de repressão à oposição durante a ditadura portuguesa] que estava atenta e que identificava e que se visse alguma coisa que não percebesse ou que não... censurava... censura! (INF. 2, 2013).

$\mathrm{O}$ discurso do entrevistado indicou que, ainda que estivessem sujeitos às retaliações, os foliões aproveitavam-se das fantasias de Carnaval para, de alguma forma, contestar o regime ditatorial. A prática parece persistir nas manifestações contemporâneas, como se infere a partir das mencionadas placas com anedotas de caráter crítico. No entanto, no que tange aos enredos das Escolas de Samba, observou-se uma opção por temas mais amenos, como se constatou nos enredos adotados pelas agremiações nas últimas edições do evento (FUNDAÇÃO DO CARNAVAL DE OVAR, 2012).

O esforço de organização dos festejos de Carnaval, iniciado em 1952, foi evoluindo e ganhando contornos de um evento minuciosamente planejado, na medida em que ganhou importância econômica, midiática e passou a figurar como um dos principais atrativos turísticos da cidade (COLARES PINTO, 1993). 
De acordo com informações disponíveis na página da Câmara Municipal de Ovar (2013), na qual se discorria acerca das seis décadas de Carnaval organizado na cidade, contemporaneamente o município contava com quatro escolas de samba, cada qual com cerca de 150 componentes e 20 grupos que, por sua vez, dividiam-se em duas categorias: Grupos de Passarela e Grupos Carnavalescos. Essa divisão remonta ao ano de 1992 e atende à necessidade de estabelecer critérios para avaliação e premiação dos grupos:

Os prêmios monetários atribuídos aos Grupos e Escolas de Samba são, na verdade, insignificantes, mas a vontade de apresentar o melhor trabalho e de o ver reconhecido, faz com que as classificações sejam levadas muito a peito. Para uma melhor avaliação, em 1992 dividem-se os grupos em duas categorias: Passerelle e Carnavalescos. Também em 1992, surge um novo grupo cujos elementos (todos do sexo feminino) são quase todos ex-participantes em Escolas de samba: As Joanas d'Arco da Velha. Estas meninas integram o corso introduzindo, com grande sucesso, uma forma de desfile cuidadosamente organizada que rapidamente foi assimilada pelos restantes grupos da categoria Passerelle (OVAR, 2013 - Grifos do autor).

A divisão dos grupos por gênero revela um certo conservadorismo moral à época da criação das categorias, já que aparentemente a execução de coreografias por pessoas do sexo masculino era vista com algumas ressalvas (INF. 2, 2013). No entanto, resquícios desses traços ainda parecem subsistir:

E se nós dividirmos os tais Grupos de Carnaval e os de Passarela, os de passarela é um grupo... embora haja homens e mulheres em ambos, mas os de passarela é um grupo mais vocacionado para trajes mais elegantes, mais costura... muito ricos, mais ricos! [...] Predominantemente feminino. E onde se entende bem e faz sentido essa questão de ter uma coreografia ensaiada, e até algo que é muito importante em termos depois de votação final (INF. 2, 2013).

Assim, oschamados Grupos de Passarela ainda permaneceram com uma formação quase exclusivamente feminina, enquanto nos Grupos de Carnaval predominavam os homens:

\begin{abstract}
Na parte dos grupos carnavalescos o que é então, a maior parte, onde então entra a piada e é mais gostoso [...] acaba por ser engraçado porque... imaginar homens... e agora é misto, mas a maioria também é homem aí... a fazer um... de dançarinos, entrar ali encaixadinhos... é uma festa onde há exageros não é? Isso também é uma forma de tornar a coisa cômica, né? Mas evoluiu para aí em algum sentido... na minha forma de ver, às vezes é prejudicial porque as pessoas também gostam dessa interação, e todas vezes isso não acontece (INF. 2, 2013).
\end{abstract}

A tendência de apresentação de coreografias ensaiadas mesmo pelos grupos carnavalescos encontrava algumas resistências, mesmo ao gestor público que concedeu a entrevista, que pareceu temer pela perda da interação com o público e da espontaneidade original desses grupos.

Em setembro de 2013, no transcurso da atividade de campo da presente investigação, a estrutura física do Carnaval de Ovar passou por uma importante modificação. Conforme Oliveira (2013), na ocasião ocorreu a inauguração da chamada "Aldeia do Carnaval", um conjunto de 24 pavilhões, destinados a acolher as quatro escolas de samba e os 20 grupos que desfilam na cidade. A mesma fonte acrescentou que, além dos pavilhões, havia ainda três armazéns, duas oficinas, enfermaria, instalações sanitárias privadas e comuns e um palco para realização de shows e eventos. Esse equipamento também apresentava semelhanças com a Cidade do Samba, no Rio de Janeiro, estrutura onde funcionam os barracões das escolas de samba cariocas, conforme se constatou em visita realizada durante a pesquisa.

A Aldeia do Carnaval viria a servir como base para a montagem das fantasias, alegorias e ensaios das escolas e grupos pela primeira vez para o Carnaval de 2014 (INF. 2, 2013). Os integrantes das escolas pareciam estar satisfeitos com o fato de dispor de um pavilhão sem a necessidade de pagar aluguel, mas queixavam-se da dimensão deste (a área, de aproximadamente $150 \mathrm{~m} 2$ é igual para grupos e escolas de samba). Além do aspecto funcional, em relação aos ensaios e preparação das fantasias, o espaço também poderia servir de local para realização de eventos, como assinalou um dos gestores públicos ligados à esfera cultural na cidade: 
A festa tem dois momentos. Tem um momento que é o chamado desfile de Carnaval... e que toda gente tem acesso, é pra isso que todos nós trabalhamos, todos nós porque isso envolve dois mil participantes, portanto pessoas que participam mesmo do Carnaval, mais os familiares, na cidade de Ovar mesmo, envolve muita gente no âmbito do Carnaval. Pronto, nós tínhamos antigamente as sedes próprias, espaços diferentes alugados, com menos condições de que as que viram, neste momento estamos concentrados no que chamamos a 'Aldeia do Carnaval' e portanto essas pessoas participam durante dois, três meses, vamos lá, na organização e na execução dos fatos, mas também em momentos de relax... esses... vem junto à cidade, ao centro da cidade ... onde se organizam algumas festas, onde as pessoas se juntam, comem e bebem... (INF. 2, 2013).

Na visita de campo, realizada em outubro de 2013, foi possível observar que a Aldeia estava afastada da cidade cerca de $4 \mathrm{~km}$, o que causava alguma dificuldade de acesso e limitava a interação, segundo depoimentos informais de populares. Em contrapartida, os mesmos informantes também assinalaram que essa distância permitia que festas ou ensaios se prolongassem pela noite e madrugada, já que se situava em uma zona industrial. Integrantes dos grupos relataram que a localização da aldeia em área distante do centro deveu-se às reclamações e conflitos com uma parcela dos moradores, em função do barulho. Por outro lado, os donos de bares e cafés se ressentiam pela perda de clientes decorrente da mudança no local dos ensaios.

O desfile é realizado em uma das ruas da cidade, sendo que recentemente havia sido transferido do Centro Histórico para uma avenida mais afastada (que dava acesso à Aldeia do Carnaval) onde eram montadas arquibancadas provisórias para as quais o acesso era pago (INF. 2, 2013).

Alguns populares referiram em conversas informais que as mudanças recentes alteraram a concepção de Carnaval da cidade. Através da observação de campo se colheu expressões como: "Quando o Carnaval não era um negócio...."

Verificou-se, no entanto, haver um sensível esforço, tanto de representantes do poder público como das Escolas e Grupos em valorizar a população local como protagonista do Carnaval, embora se admitisse as influências externas no modelo do evento. Nesse sentido, eram recorrentes as críticas ao Carnaval da vizinha cidade de Estarreja, que, na opinião dos vareiros interpelados pela pesquisa, adotava práticas diversas das de Ovar na escolha dos Reis e Rainhas. Ali, estes seriam selecionados entre celebridades da televisão e cinema, inclusive e especialmente artistas da Rede Globo de Televisão, já que as novelas da emissora, na ocasião, eram muito populares em Portugal (INF. 2, 2013). Quando perguntado acerca da cobertura da imprensa ao Carnaval de Ovar, um dos entrevistados aludiu às estratégias usadas pelos vizinhos:

[...] não temos tirado grande proveito da televisão, não temos isto também pelo fato de as televisões terem interessado por carnavais onde têm como elemento de referência o chamado "Rei do Carnaval" famosos [...]! Alguns até das novelas brasileiras [...]. São muito populares por aqui, portanto numa tentativa de deslocação das pessoas com o intuito de ver e, se calhar não tanto o Carnaval ... pessoalmente sempre fui contra, nós em Ovar sempre tivemos essa figura do rei de gente nossa, daqui da casa, e sempre apostamos naquilo que é o nosso trabalho [...], naturalmente o que sentimos de mídia não tem tanto interesse como terá outro qualquer. Portanto, há alguma deficiência, algumas coisas que temos identificadas, mas que trabalhamos no sentido de melhorar, mas, comunicação é feita através de redes sociais, internet e cartazes que são espalhados [...]. Privilegiar sempre... gente da terra! É quase um estatuto que temos aqui. Gente da terra! (INF. 2, 2013).

Em outro ponto da conversa, respondendo sobre o que considerava ser singularidade do Carnaval local, o entrevistado reforçou a preferência pela utilização de moradores da cidade como protagonistas da festa: "Eu poderei dizer que é utilizar a gente da casa [...]. Temos aqui vizinho, o Carnaval de Estarreja, que por norma utilizam Rei alguém que... 'compram’ pra esta festividade! E nós, desde a gênese, o Rei e a Rainha do Carnaval são pessoas de cá, da casa!" (INF. 2, 2013). O mesmo tipo de observação também estava sendo frequente em fóruns de discussão sobre o tema na Internet e nas redes sociais eletrônicas da região. 
Além dos desfiles na avenida, que acontecem nas noites de domingo e terça-feira, também havia pequenos grupos que saiam fantasiados pelas ruas e bares da cidade no período de Carnaval (INF. 2, 2013).

Ainda de acordo com o entrevistado (INF. 2, 2013), havia ocasiões em que o desfile de Carnaval era suspenso ou cancelado em uma ou duas noites em razão de intempéries meteorológicas, o que revelava parte das dificuldades da adoção de um Carnaval "tropical" no período que corresponde ao inverno europeu.

No caso de Ovar, pareceu evidente a ocorrência de um processo de hibridização cultural na formatação da festa, especialmente quando se avalia a inserção de elementos típicos do Carnaval brasileiro, e particularmente carioca.

\section{Conclusão}

A realização do presente estudo proporcionou algumas possibilidades de interpretação do processo de ressignificação das tradições de Carnaval no Norte de Portugal. Entre outros aspectos, pode-se mencionar a influência do turismo sobre as manifestações culturais, a espetacularização e transformação de rituais em performances, a importância das textualizações acadêmicas e jornalísticas sobre as festividades, as diferentes velocidades em que as mudanças ocorrem, o papel dos organizadores na seleção de conteúdos culturais e a própria natureza dinâmica das tradições que possibilita sua invenção e ressignificação.

Entre os aspectos observados, notou-se que os organizadores realizavam um esforço para moldar a festa segundo aquilo que acreditavam ser as expectativas dos visitantes e, dessa forma, considerou-se ser possível afirmar que o turismo estava tendo um papel ativo na definição dos contornos da manifestação que gradativamente vai perdendo seu caráter de ritual e se transformando em uma performance, ou seja, de certa forma é espetacularizada.

À perda de autenticidade, no entanto, contrapõe-se o argumento de que a ressignificação da manifestação parece ser a alternativa ao seu desaparecimento. As evidências observadas demonstraram que, especialmente no caso de Podence (mas também em Ovar) o Carnaval dava mostras de fragilização antes de ser reabilitado, por assim dizer, como atração turística.

Além disso, pareceu não haver uma tradição em forma pura - original ou autêntica; todas teriam sido inventadas em determinado momento ou fruto da dinâmica interativa entre culturas e práticas sociais. Mesmo o que aparentemente não havia se alterado, na realidade passava por transformações, que em alguns casos não são percebidas em função da velocidade em que ocorrem e das estratégias adotadas para simular a perpetuação dessa "tradição".

As diferentes experiências das festas de Carnaval aqui delineadas sugerem que algumas manifestações ou arranjos foram menos suscetíveis aos efeitos da dromocracia, como Trivinho (2005) denomina a velocidade da dinâmica cultural. Em ambos os casos, no entanto, os promotores adotaram discursos e práticas de patrimonialização e tentaram criar uma imagem de manutenção de traços pretensamente autênticos, singulares e tradicionais dos eventos. 
No caso de Podence, que se trata de uma aldeia rural situada em uma das áreas mais remotas de Portugal e que estava atravessando um processo de profundas transformações típicas de um contexto de pós-ruralidade (RAPOSO, 2010), a velocidade da mudança ou o desaparecimento de antigas práticas culturais pareceu causar algum desconforto entre os moradores remanescentes e os migrantes. Assim, essas pessoas aparentemente buscavam no Carnaval e na saída dos Caretos uma espécie de contato nostálgico com algo que não existe mais, um retorno às raízes ligado à memória afetiva que se tem em relação ao lugar. Para atender a essa demanda, essas manifestações são recriadas sob uma aura de autenticidade que atrai também os turistas interessados em sua tipicidade.

Nesse processo de recriação, os organizadores estavam levando em conta sua própria experiência como frequentadores de antigas edições da festa e fazendo uma seleção subjetiva e relativamente arbitrária do que lhes parecia relevante, já que eles próprios mantinham uma relação emocional com a manifestação, o que se refletia sobre o modelo que tentavam imprimir ao evento (RAPOSO, 2010).

Para os efeitos da pesquisa, importa menos a autenticidade de fato das manifestações que a atribuição desse estatuto pelos visitantes na relação que desenvolvem com o lugar. Em outros termos, considerando que nenhuma tradição é perene, no sentido de que necessariamente sofre as alterações determinadas pela dinâmica da história, o que efetivamente interessa à análise é a impressão que os turistas tenham de que estão experienciando um evento tradicional e autêntico e não a inalcançável e idealizada pureza de uma manifestação já extinta na sua forma anterior.

\section{Referências}

ASSOCIAÇÃO DOS CARETOS DE PODENCE. Sítio Oficial dos Caretos de Podence. 2013. Disponível em: 〈http://caretosdepodence.no.sapo.pt/〉. Acesso em: 20 nov. 2013.

CÂMARA MUNICIPAL DE MACEDO DE CAVALEIROS. Página Eletrônica Oficial. Disponível em: «www.cmmacedodecavaleiros.pt>. Acesso em: 08 nov. 2013.

CÂMARA MUNICIPAL DE OVAR. Página Eletrônica Oficial. Disponível em: 〈http://www.cm-ovar.pt〉. Acesso em: 25 nov. 2013.

COLARES PINTO, A. H. Memória do Carnaval. In: FERnANDES, R.; ROCHA, A; RODRIGUES, D. Carnaval de Ovar: 1952 - 1993. Santa Maria da Feira: Gráfica Feirense, 1993. Cap. 1, p. 10-18.

FERNANDES, R.; ROCHA, A; RODRIGUES, D. Carnaval de Ovar: 1952 - 1993. Santa Maria da Feira: Gráfica Feirense, 1993.

FILIPPIM, M. L. A invenção de uma tradição carnavalesca: o carnaval de Matinhos - Paraná (Brasil) sob a perspectiva dos organizadores. 2015. $191 \mathrm{f}$. Tese (Doutorado) - Curso de Geografia, Programa de Pós-Graduação em Geografia, Universidade Federal do Paraná, Curitiba: 2015.

FRANCHINI, A. S.; SEGANFREDO, C. As 100 melhores histórias da mitologia: deuses, heróis, monstros e guerras da tradição greco-romana. 9. ed. Porto Alegre: L\&PM, 2007.

FUNDAÇÃO DO CARNAVAL DE OVAR. Carnaval Ovar 2012. Realização de Guilherme Terra. Ovar: Fundação do Carnaval de Ovar, 2012. 1 DVD, son., color. 
INSTITUTO NACIONAL DE ESTATíStICA. Portal do INE. Disponível em: 〈https://www.ine.pt/xportal/ xmain?xpid=INE\&xpgid=ine_main>. Acesso em: 26 nov. 2013.

MARTINS, J. S. A Carnavalização do quotidiano: uma perspectiva psicossocial. Revista da Faculdade de Ciências Humanas e Sociais. Porto: Universidade Fernando Pessoa, v. 6, p. 128-134, 2009.

MÁSCARAS. Direção de Noémia Delgado. Lisboa: Centro Português de Cinema, 1976. (116 min.), son., color. Disponivel em: 〈http://www.youtube.com/watch?v=6WjcZND10OM〉. Acesso em: 24 nov. 2013.

MUNIZ JÚNIOR, J. $O$ universo místico do Carnaval. Santos: Novo Milênio, 28 jan. 2003. Número Especial - Carnaval, p. 1-4. Disponível em: 〈http://www.novomilenio.inf.br/festas/carna05.htm〉 Acesso em: 05 nov. 2013.

OLIVEIRA, S. D. Ovar tem uma aldeia onde o Carnaval já chegou, para ficar sempre presente. Público. Lisboa, p. 24-24. 15 set. 2013. Disponível em: 〈http://www.publico.pt/local-porto/jornal/ovar-temuma-aldeia-onde-o-carnaval-ja-chegou-para-ficar-sempre-presente-27092810〉. Acesso em: 10 nov. 2013.

OVAR. Câmara Municipal. Seis décadas de Carnaval organizado. Disponível em: 〈http://www. carnaval.ovar.net/node/28>. Acesso em: 26 nov. 2013.

RAPOSO, P. Por detrás da máscara: ensaio de antropologia da performance sobre os caretos de Podence. Lisboa: Instituto dos Museus e da Conservação, 2010.

- Virando o outro em Podence: máscaras da pós-ruralidade. Revista Antropolítica. Niterói: Universidade Federal Fluminense, n. 30, p. 131-149, 2011.

ROSÁRIO, M. E. do. Nós por cá: tradições do nordeste transmontano. 122 f. Dissertação (Mestrado) Curso de Mestrado em Cultura Portuguesa, Universidade de Trás-os-montes e Alto Douro. Vila Real: Portugal, 2008.

TRIVINHO, E. Introdução à dromocracia cibercultural: contextualização sociodromológica da violência invisível da técnica e da civilização mediática avançada. Revista Famecos. Porto Alegre: n. 28, p. 63 77, dez. 2005.

VAZ PINTO, D. P. $O$ turismo em Ovar entre 1945 e 1960. 139 f. Dissertação (Mestrado) - Curso de História Contemporânea, Faculdade de Letras, Porto, Portugal: Universidade do Porto, 2011.

YIN, R. K. Estudo de caso: planejamento e métodos. Porto Alegre: Bookman, 2001. 